\title{
IMPLANTAÇÃO E GERENCIAMENTO DO CENTRO DE INSPEÇÃO NO PROGRAMA DE I/M
}

\author{
Luiz Vicente Figueira de Mello Filho ${ }^{\mathrm{a}}$ \\ Flávio Miguel $^{\mathrm{b}}$ \\ Andrea Lucia Gouvinhas ${ }^{\mathrm{c}}$ \\ José Ricardo Vieira $^{\mathrm{d}}$ \\ Ricardo Mois Baracat ${ }^{\mathrm{e}}$ \\ Luiz Rodrigues de Sousa ${ }^{\mathrm{f}}$ \\ Douglas da Silva Gameiro ${ }^{\mathrm{g}}$
}

\begin{abstract}
This work presents the methodology used for managing I/M Program (Inspection and Maintenance) in Inspection Centers since the implementation to operation. The study covers all the technical details that might cause environmental impacts in the neighborhood and Inspection Centers, also highlights the technical standardization and relationship with the citizen, since scheduling by website to ensure the electronic data transfer to São Paulo city government (PRODAM). The inspection process is performed on all inspection centers, in a standardized way, in order to ensure uniformity of technical inspection results. Also it was developed and deployed in mid-2010 the Integrated Management System (IMS) for all processes can be managed in a systemic way, which aims to ensure operational technical excellence. So there is the improvement in the availability and confidentiality of information that allows measuring the I/M program benefits. This method of managing the Inspection Centers showed to São Paulo city the benefits widely available due to the centralized management model of current concession.
\end{abstract}

Key-words: I/M program. Management. São Paulo.

\section{RESUMO}

Este trabalho apresenta a metodologia utilizada para o gerenciamento dos Centros de Inspeção do Programa de I/M (Inspeção e Manutenção) desde a implantação até a operação. O estudo abrange todos os detalhes técnicos que possam causar impactos ambientais na vizinhança e nos Centros de Inspeção, também destaca a padronização técnica e o relacionamento com o munícipe, desde o agendamento via website até a garantia da transferência eletrônica destes dados à Prefeitura de São Paulo (PRODAM). O processo de inspeção é executado em todos os Centros de Inspeção, de maneira padronizada, com o propósito de garantir a uniformidade técnica dos resultados da inspeção. Para que todos os processos possam ser gerenciados de forma sistêmica, foi desenvolvido e implantado em meados de 2010 o Sistema de Gestão Integrado (SGI), que objetiva garantir excelência técnica operacional. Com isso houve o aprimoramento quanto à disponibilidade e confidencialidade das informações que permitem mensurar os benefícios do programa de I/M. Este método de gerenciamento dos Centros de Inspeção apresentado trouxe para a cidade de São Paulo inúmeros benefícios amplamente divulgados em função do modelo centralizado de gestão de concessão atual.

Palavras-chave: Programa de I/M. Gerenciamento. São Paulo.

a,b,c,d,e,f e g Gerente da Controlar S/A 


\section{INTRODUÇÃO}

Em 1995 a prefeitura de São Paulo lança o edital de licitação de ${ }^{\circ} 02$ da Secretaria do Verde e do Meio Ambiente com a iniciativa de implantar a inspeção ambiental veicular.

O Consórcio Controlar vence a licitação, cria-se a Controlar SA - empresa de propósito específico (EPE) para execução do Programa de Inspeção e Manutenção de Veículos em Uso (I/M-SP), e assina em janeiro de 1996, o contrato com a Secretaria do Verde e do Meio Ambiente da cidade de São Paulo, concessão n ${ }^{0}$ 34/SVMA/1995 - Programa de I/M-SP.

O contrato não prosperou devido à suspensão por iniciativa do Governo do Estado do Convênio entre o Estado e Município de São Paulo que definia a obrigatoriedade da aprovação na inspeção para o licenciamento do veículo.

Em junho de 2001 foi assinada a Ordem de Serviço, que, entretanto veio a ser suspensa, sendo somente em junho de 2007, revogada a suspensão da Ordem de Serviço de 07/06/2001, e determinada à elaboração de cronograma para implantação do Programa I/M-SP para os veículos licenciados na cidade de São Paulo.

No mês de maio de 2008 foi iniciado o Programa I/M-SP, com a inspeção obrigatória para toda a frota de veículos do ciclo Diesel.

Em 2009, todas as motocicletas, excluso veículo de Dois Tempos, e os automóveis de 2003 a 2008 complementaram a frota alvo inspecionada.

No ano de 2010 a inspeção passou a ser para todos os veículos licenciados na cidade de São Paulo, independentemente do ciclo do motor, exceto para veículos de Dois Tempos, híbridos (movido por motor de combustão interna e elétrico), de coleção, os concebidos unicamente para aplicações militares, agrícolas, de competição, tratores, máquinas de terraplenagem e pavimentação e outros de aplicação ou de concepção especial sem procedimentos específicos para obtenção de Licença para Uso da Configuração de Veículo ou Motor - LCVM.

De 2011 em diante a inspeção de ruído, que anteriormente não era reprobatório, sendo feita apenas para levantamento de dados para pesquisa e desenvolvimento, torna-se item obrigatório para a inspeção ambiental, passando a ser um dos motivos de possível não aprovação e de impedimento do licenciamento. Os veículos com ano de fabricação igual ou abaixo de 1965 ficam dispensados da inspeção ambiental.

De forma gradativa, o gerenciamento do centro de inspeção tornou-se mais complexo, tendo um aprendizado conforme o número de veículos da frota alvo foi aumentando em função dos anos de fabricação e tipos de veículos a serem inspecionados. 


\section{IMPACTOS AMBIENTAIS NA VIZINHANÇA, NO TRABALHO E NOS MUNÍCIPES USUÁRIOS DO CENTRO DE INSPEÇÃO}

Atualmente há dezesseis centros de inspeção localizados em cada região na cidade de São Paulo (Figura 1), que foram selecionados entre centenas de ofertas de terrenos disponíveis no município. Porém, na maioria deles com alguma pendência legal que impossibilitava a efetivação para o contrato de locação e a construção das instalações dedicadas exclusivamente para a inspeção de veículos.

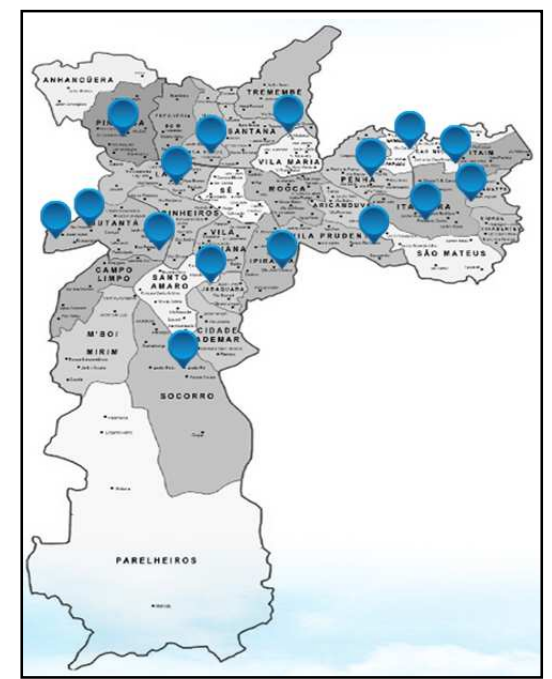

Figura 1: disposição dos centros de inspeção na cidade de São Paulo.

Questões como isolamento da área em função da identificação de nascente d'água, compensação de árvores devido às instalações civis e adequação da área construída de acordo com a disposição arbórea foram priorizadas pontualmente para que fossem mitigadas interferências com os terrenos escolhidos.

Estudos das vizinhanças quanto ao fluxo de veículos, atividades no entorno como área residencial, centro comercial, indústria de bem de capital e de consumo foram analisadas quanto ao impacto que causaria com a demanda média de 1.287 veículos circulantes nos meses de alto agendamento com o propósito de estarem no local exclusivamente para a concretização do serviço de inspeção ambiental (CONTROLAR, 2011).

Os veículos que passam pelo processo de inspeção vão desde uma motocicleta de pequeno porte até um ônibus biarticulado, podendo a inspeção ser concluída após a análise de gases poluentes para o ciclo Otto, opacidade para o ciclo Diesel ou após ser verificado pelo medidor de nível sonoro.

Também foi contemplada in loco a análise de gases poluentes presentes em cada centro de inspeção assim como o ruído com o cumprimento estabelecido na Norma Regulamentadora (NR) nº 09 da Portaria 3214/78 do Ministério do Trabalho em seu item 9.1.5: 
"consideram-se riscos ambientais os agentes físicos, químicos e biológicos existentes nos ambientes de trabalho que, em função de sua natureza, concentração ou intensidade e tempo de exposição, com capacidade de causar danos à saúde do trabalhador".

A análise por meio da NR $n^{\circ} 07$ da Portaria 25/94 que representa o Programa de Controle Médico de Saúde Ocupacional (PCMSO) em cada Centro de Inspeção também contribuiu na verificação da qualidade do ar no local referente aos munícipes que ficam em média de 13 a 15 minutos de permanência aguardando a finalização das inspeções dependendo do automóvel, motocicleta e veículo pesado (CONTROLAR, 2011).

\section{O CENTRO DE INSPEÇÃO}

O gerenciamento do Centro de Inspeção segue três pilares da qualidade total (CAMPOS, 1999): liderança, conhecimento técnico e método, sendo todos os pilares utilizados na organização. Destes, utilizamos para a execução e andamento dos trabalhos na inspeção ambiental veicular a tecnologia empregada, a competência das pessoas e o cumprimento da legislação, que estão representadas por um triângulo equilátero a interação entre eles.

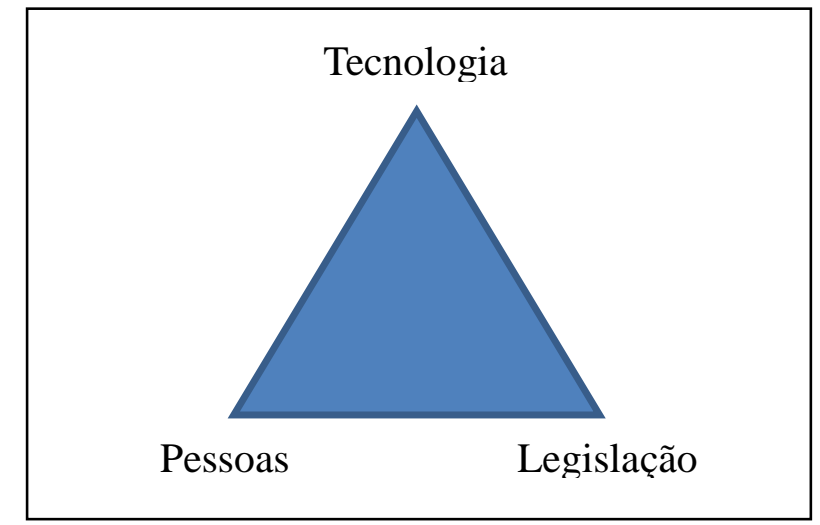

Figura 2: desenho esquemático da interação entre os vértices do triângulo.

\subsection{Tecnologia}

Para atingir com sucesso o número de 4.170.240 inspeções (CONTROLAR, 2011) há um complexo sistema que se inicia pela disponibilidade dos serviços, desde a emissão de guia de recolhimento da tarifa, o agendamento feito pelo website da concessionária ou por telefone do call center até a entrega eletrônica dos resultados das inspeções à Empresa de Tecnologia da Informação e Comunicação do Município de São Paulo (PRODAM).

Por trás do acesso que o munícipe faz para o agendamento, há um fluxo de informações entre o Data Center com os servidores dos centros de inspeção e a PRODAM, que garantem com facilidade a liberação do licenciamento sem o contato físico com o resultado da inspeção para os veículos aprovados no prazo máximo de 72 horas. 
Diariamente há uma rotina de verificação no departamento de Tecnologia e Informação (TI) e Engenharia de Manutenção de mais 110 itens de forma preventiva. Conforme CAMPOS (2004), o gerenciamento da rotina do trabalho no dia a dia é definido como:

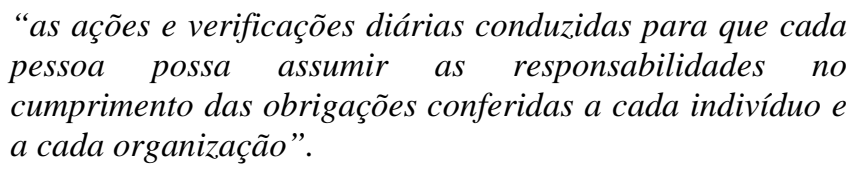

O monitoramento de todo os sistema eletrônico, incluso toda a comunicação e transferências de dados, também é feito 24 horas por dia, sete dias por semana, que possibilita a ação corretiva, sem causar impactos à operação, que em uma análise da causa raiz, emprega-se como item de checagem por meio do PDCA (Planejar-Executar-Verificar-Ajustar).

O departamento de TI e Engenharia de Manutenção tem uma disponibilidade de 99,99\% em operação na presente data. Para se chegar nesta alta disponibilidade, os sistemas estão implantados em dois Data Centers. Se o serviço do website principal por algum motivo venha a interromper os trabalhos, o Data Center backup é acionado automaticamente. Os níveis de contingência para manter todos em perfeito funcionamento requerem a duplicação de equipamentos, links de comunicação, softwares de inspeção e procedimentos de atualização de dados e controles.

As rotinas estabelecidas em procedimento visa à proteção de possíveis invasores internos, tornando o constante investimento em apliances e softwares que garantem a integridade dos dados da concessionária, a confidencialidade de todas as informações e mitiga o risco de invasões externas ao ambiente.

Cada centro de inspeção dispõe de uma área técnica com equipamentos que sustentam toda a infraestrutura de operações possibilitando os processos de inspeção de forma continuada.

A área de operações conta com um Centro de Processamento de Dados (CPD) equipado com servidores e sistema de controle de temperatura com alerta via alarme, dois aparelhos de ar condicionado e dois No Break, que se alternam e os mantêm em operação diária de modo integral, independentemente se está ou não no horário de atividade.

Para que os equipamentos de inspeção possam operar de forma continuada e sequenciada, há dois equipamentos geradores de ar comprimido e uma rede de distribuição deste ar, com sistema de filtragem e controle de pressão e vazão, que permite a correta descontaminação e limpeza dos analisadores de gases a cada inspeção.

A energia elétrica é dividida por meio de uma nomenclatura interna conhecida como energia estabilizada, com a tensão controlada, e alternada, com a tensão proveniente que recebemos pela concessionária de energia elétrica. A primeira alimenta todos os equipamentos de inspeção, servidores e computadores, que impossibilita variações na rede de alimentação e garante o bom funcionamento destes aparelhos. A segunda alimenta todo o restante da infraestrutura da unidade.

Os painéis elétricos e sistema de aterramento são devidamente dimensionados com instrumentos de proteção, como disjuntores, chaves contatoras e relês de proteção, sendo anualmente verificados por uma análise termoelétrica. Além disto, todas as instalações 
provêm de sistema de proteção contra descarga atmosférica (SPDA), visando aumentar a segurança dos usuários, funcionários e equipamentos, e que contribui com o aumento da disponibilidade das operações.

Há um gerador de energia elétrica em cada unidade, que supri o abastecimento de energia elétrica de toda unidade quando ocorre uma falha no fornecimento pela concessionária responsável, automaticamente a energia elétrica é fornecida pelo próprio centro de inspeção.

Historicamente houve ocorrências em que o gerador chegou a operar em um determinado centro de inspeção por cinco dias ininterruptamente.

O sistema de redundância na infraestrutura busca atender o munícipe no horário agendado, evitando filas no centro de inspeção, que possam afetar o trânsito externo à empresa prestadora do serviço.

A confiabilidade e robustez dos equipamentos no entorno da inspeção mantém a operação sem paradas e uniformiza as inspeções do ciclo Diesel e Otto de forma que os resultados das inspeções não são afetados por efeitos externos.

O software de inspeção, devido à interação da Engenharia de Produto e TI, possibilita que atualizações nas tabelas de parâmetros utilizadas para cada veículo específico no ciclo Diesel, e para a medição de ruído sejam feitas em até 24 horas da publicação no Diário Oficial do município de São Paulo (DOM), em todos os dezesseis postos simultaneamente, de modo que o munícipe terá os mesmos limites, independentemente do centro escolhido.

Por meio de avaliações sistemáticas nos processos de inspeção, é utilizado o FMEA (Failure mode and effect analysis - Análise do Efeito e Modo de Falha), que permite identificar oportunidade de melhoria na atualização do software com o propósito de dirimir dúvidas e interpretações com foco na padronização entre as inspeções e ao combate à fraude.

Desta forma, o trabalho associado à tecnologia embarcada no entorno como no propósito fim, possibilita a uniformização dos resultados que contribuem em estudos divulgados pela Faculdade de Medicina da Universidade de São Paulo (FMUSP), pela própria concessionária, e também, para futuros projetos em grupos de trabalho coordenados pela Associação dos Engenheiros Automotivos (AEA), devido ao banco de dados com mais de catorze milhões de inspeções já realizadas.

Além disso, o modelo centralizado contribui com dados consistentes com a possibilidade de traçar o perfil e a significância da frota-alvo para a poluição do ar, o estado geral da manutenção da frota, utilização de instrumentos e equipamentos de testes precisos, verificados e atualizados simultaneamente, e entre outros benefícios, a aceitação da população com o programa de I/M (BRANCO et al, 2012).

\subsection{Pessoas}

Para que as pessoas, que atuam na empresa de propósito específica voltada à inspeção ambiental pudessem colocar em prática a estratégia definida pela alta administração, foi adotado um sistema gerencial conhecido como Balanced Scorecard. 
Este sistema equilibrado é organizado em quatro perspectivas distintas, que são: finanças, clientes, processos internos, e aprendizado e crescimento (KAPLAN; NORTON, 1997), que foram adaptadas internamente como: resultados financeiros, mercados e clientes, processos internos e competências.

O Balance Scorecard fornece uma estrutura necessária para a tradução da estratégia em termos operacionais, que possibilita que cada funcionário tenha entendimento da importância de sua atividade no contexto geral da empresa (KAPLAN; NORTON, 1997).

Cada uma das perspectivas tem indicadores de desempenho que interagem entre si e possam alavancar as ações definidas no planejamento estratégico, isto é, os resultados dos indicadores da base formada pela perspectiva competência, influenciam os processos internos, que impactam em mercados e clientes, e consequentemente, os resultados financeiros.

Com o intuito de aplicar uma competição saudável entre as dezesseis unidades e em função da particularidade de cada local com a frota inspecionada, todos os indicadores de desempenho tem uma meta de melhoria que compara o próprio centro de inspeção com os resultados do ano anterior.

No nível operacional há o pagamento salarial adicional, chamado de variável, que contribui no esforço em conjunto para se alcançar a maior pontuação dos indicadores e motiva mensalmente a ganhar pontos em cada uma das perspectivas.

Além disso, mensalmente é divulgado o ranking dos centros de inspeções para que seja um direcionamento de qual unidade está se sobressaindo e qual o motivo que o levou a chegar a um determinado resultado. Aplica-se naturalmente o benchmarking entre as unidades.

Esta metodologia também vai de encontro com os cinco objetivos de desempenho na produção, que são: qualidade no serviço prestado, velocidade que é executado, a confiabilidade na entrega do resultado, a flexibilidade dos tipos de veículos que fazem a inspeção e consequentemente vantagens quanto à elaboração do custo, que pode ser gerido em função do bom atendimento das atividades anteriores (SLACK, 2009).

As perspectivas são apresentadas em seguida.

\subsubsection{Perspectiva competência}

Na perspectiva competência está diretamente relacionado com os pré-requisitos na formação para contratações, com os treinamentos internos para novos funcionários e reciclagem dos atuais ou recém-promovidos para exercerem a função específica do cargo, que possibilitarão os meios para se alcançar as metas medidas pelos indicadores.

Para isto, conforme o grau de instrução do funcionário e vontade própria em crescer na empresa, há um plano de carreira com cinco níveis operacionais e dois níveis de gestão em cada centro de inspeção veicular que garante que o funcionário almeje melhorar a sua posição na empresa a partir dos resultados que apresenta ao longo do trabalho. Como isso, o turnover de saída espontânea foi de 4,49\%, que representou 29 pedidos de demissão no ano passado. 
As vagas são divulgadas pelo departamento de Recursos Humanos internamente e depois para o mercado de trabalho de modo que na política da empresa há a cultura de identificação de talentos inicialmente dentro da organização.

Em 2012 foram feitas 61.675 horas de treinamento voltado à inspeção e foram promovidas 326 pessoas de modo que representou $71 \%$ das vagas abertas preenchidas com o recrutamento interno.

Os cargos operacionais passam em sua totalidade por uma avaliação de eficácia, conhecida como TPPA - Treinamento Prático no Piso Azul, que valida à parte conceitual na prática antes de exercer uma determinada função. A denominação "piso azul" é devida a todos os centros de inspeção ter o piso azul na área de verificação dos veículos.

Com estes controles é possível mitigar os acidentes de trabalho, desvios nos processos e absenteísmos, que são indicadores desta perspectiva.

\subsubsection{Perspectiva processos internos}

A inspeção ambiental veicular é feita conforme três principais macroprocessos, que são: Agendar, Inspecionar e Informar. Para que estes processos sejam conduzidos normalmente no centro de inspeção, há mais onze macroprocessos de apoio e seis de gestão, que suportam e mantém o rigor da qualidade das inspeções.

O primeiro macroprocesso visa garantir o acesso do munícipe na realização do pagamento da tarifa de inspeção e no agendamento em um dos dezesseis postos na cidade de São Paulo. A área de planejamento, que é apoio a este macroprocesso, tem a função essencial de disponibilizar as vagas que melhor se adequa às necessidades do munícipe, isto é, garantir que via website ou por telefone do Call Center da concessionária, uma projeção para que se tenha um horizonte de agendamento considerável para atender na maioria das vezes a data e hora escolhida pelo munícipe.

O macroprocesso inspecionar é o responsável pela padronização das inspeções de acordo com a configuração dos veículos licenciados no município de São Paulo, de modo que no ciclo Diesel tem os veículos leves (VUCs, vans, camionetas e SUVs) e pesados (caminhões e ônibus convencional, articulado e biarticulado) e no ciclo Otto os veículos leves (automóveis, camionetas e SUVs), pesados (caminhões) e motociclos (motocicletas, triciclos, quadriciclos e scooters). Este macroprocesso tem o maior número de apoios na operação, sendo este o gerador da receita da empresa.

Por último, o macroprocesso Informar tem um papel fundamental que é garantir que o resultado da inspeção seja informado inicialmente no final da prestação de serviço com o laudo impresso e entregue ao munícipe, e garantir que os dados da inspeção sejam enviados à PRODAM em até 72 horas com total confidencialidade de informações.

Os indicadores dos processos internos estão relacionados na inspeção com a padronização visual, feita pelo funcionário qualificado e auditado por outro sem a ajuda de máquinas, a disponibilidade operacional para o agendamento e a padronização computadorizada, que 
utiliza a tecnologia e as rotinas de verificação. O controle é feito pela área de TI e Engenharia de Manutenção, sendo as verificações validadas por meio das auditorias de infraestrutura.

Deste modo os departamentos se interagem devido não ter um processo isolados por área específica, sendo que o fluxo de comunicação é feita pelo nível operacional e as particularidades e melhorias no processo são definidas pelo nível gerencial por meio do PDCA.

Além disso, utiliza-se o conceito Lean Manufacturing na elaboração dos processos, isto é, procura-se eliminar as sete categorias de desperdício (OHNO, 1997), que são: produção em excesso, no qual se trabalha somente com o agendamento; movimentação, que o próprio munícipe faz em grande parte da operação; espera, que tem um controle rigoroso dos 30 minutos de permanência do munícipe no centro de inspeção; transporte, que praticamente não temos em função do munícipe se direcionar ao local; os estoques desnecessários, que há o controle dos insumos voltados à inspeção; processamento desnecessário, que se faz exatamente o que é definido na legislação e correções, que evita-se constantemente em função dos macroprocessos e instruções definidas.

\subsubsection{Perspectiva mercado e cliente}

A perspectiva mercado e cliente é o verificador se as perspectivas competência e processos internos estão sendo executadas de acordo com o monitoramento dos indicadores. Isto é, se há um trabalho base na contratação, treinamento e reciclagem dos profissionais, há consequentemente a execução dos trabalhos relacionados aos processos internos.

Os principais indicadores nesta perspectiva é o tempo de permanência no centro de inspeção, reclamações referentes ao serviço prestado e erros operacionais. $\mathrm{O}$ tratamento de desvios nestes indicadores não necessariamente terá uma ação isolada, sendo muitas vezes a iniciativa de uma reflexão do gestor, via indicadores que se relacionam, de como foram executados os trabalhos de base para ocasionar algum hipotético desvio, gerando um plano de ação.

Por este motivo cada gestor no centro de inspeção tem esta visão em função do desenho dos macroprocessos, de modo que os indicadores direcionam cada profissional encarregado em gerir uma equipe e tomar uma decisão com parâmetros tangíveis e com maior assertividade na orientação dos profissionais operacionais.

\subsubsection{Perspectiva resultados financeiros}

Os resultados financeiros seguem o mesmo princípio da perspectiva mercados e clientes. Isto é, como há uma definição nos processos, o gerente do centro de inspeção tem o controle de como deve estar disponibilizada a mão de obra, de modo que possa atender a frota determinada por um período de tempo.

A oferta de disponibilidade de cada unidade é feita individualmente devido o conhecimento do comportamento dos munícipes, que tendem a se repetir anualmente em função da procura maior ou menor conforme a localização, opção esta que se demonstra na figura 1 . O indicador que representa este planejamento é o custo operacional de cada centro de inspeção. 
Além disso, como as unidades de negócio têm as construções voltadas ao desenvolvimento sustentável, que segue o mesmo motivo do serviço que foi contratada, todos os centros são monitorados por indicadores como consumo de água, energia elétrica e descarte de resíduos sólidos, decorrentes da execução do serviço de inspeção ambiental.

Todo o controle no dia a dia com os resultados financeiros possibilita ter um rigor, controle e assertividade no planejamento do orçamento para o ano seguinte.

\subsection{Legislação}

O Programa de Inspeção Ambiental Veicular está previsto em lei e é regulamentado em âmbito nacional.

Na Cidade de São Paulo o programa é regulamentado pelas Leis Municipais $n^{\circ} 11.733$ de 27 de março de 1995 e n ${ }^{\circ} 12.157$ de 1996, pelo Decreto Municipal no 50.232 de 17 de novembro de 2008, por Resoluções do Conselho Nacional do Meio Ambiente, bem como está prevista no artigo 104 do Código de Trânsito Brasileiro.

Todo o procedimento adotado na realização da Inspeção Ambiental Veicular é definido pelo Conselho Nacional do Meio Ambiente - CONAMA e, para o exercício 2010, os limites anteriormente adotados foram alterados e publicados na Resolução $n^{\circ} 418$ do CONAMA de 2009, que estabelece critérios para a elaboração de Planos de Controle de Poluição Veicular PCPV, para a implantação de Programas de Inspeção e Manutenção de Veículos em Uso I/M pelos órgãos estaduais e municipais de meio ambiente, determina novos limites de emissão e procedimentos para a avaliação do estado de manutenção de veículos em uso.

Em 2010 o IBAMA - Instituto Brasileiro do Meio Ambiente e dos Recursos Naturais Renováveis publicou a Instrução Normativa $n^{\circ} 06$ que estabelece o detalhamento da inspeção ambiental veicular para todos os estados brasileiros e define o procedimento da inspeção de ruído para veículos automotores em locais aberto, mas com uma área limitada como os Centros de Inspeção.

Em 2012 foram definidos pela Resolução do CONAMA $\mathrm{n}^{\circ} 451$ os novos limites para motocicletas fabricadas de 2010 em diante, sendo aplicado na cidade de São Paulo após a publicação da Portaria n 09 de 2013 da SVMA.

Além do cumprimento da legislação que determina o cumprimento e detalhamento da inspeção, há a documentação legal que mantém o centro de inspeção em operação e com os atendimentos legais. Para isto há a implantação da Gestão à Vista em cada unidade que possibilita uma rápida conferência dos prazos e a evidência que toda a documentação legal está atualizada conforme exemplo na figura 3.

O atendimento legal segue desde o CNPJ - Cadastro Nacional da Pessoa Jurídica como o Alvará de Funcionamento (Auto de Licença), Licença de Operação, AVCB - Auto de Vistoria do Corpo de Bombeiros, CAI - Certificado de Aprovação de Instalações, PPRA - Programa de Prevenção de Riscos Ambientais, PCMSO - Programa de Controle Médico de Saúde Ocupacional, Certificado de Controle de Pragas, Ata do Comitê da CIPA em função do 
número de colaboradores, Inspeção ao Local de Trabalho, Ata de Brigada e PAE - Plano de Atendimento a Emergência, entre outros.

Também há o cuidado no cumprimento das Normas Regulamentadoras (NR) do Ministério do Trabalho, desde a NR $\mathrm{n}^{\circ} 1$ classificada como disposições gerais, passando pela NR $\mathrm{n}^{\circ} 06-$ equipamentos de proteção individual (EPI), NR $n^{\circ} 10$ - segurança em instalações e serviços em eletricidade, até o detalhamento de cargos específicos com treinamentos da NR $\mathrm{n}^{\mathrm{o}} 33$ segurança e saúde no trabalho em espaços confinados até a NR nº 35 - trabalho em altura.

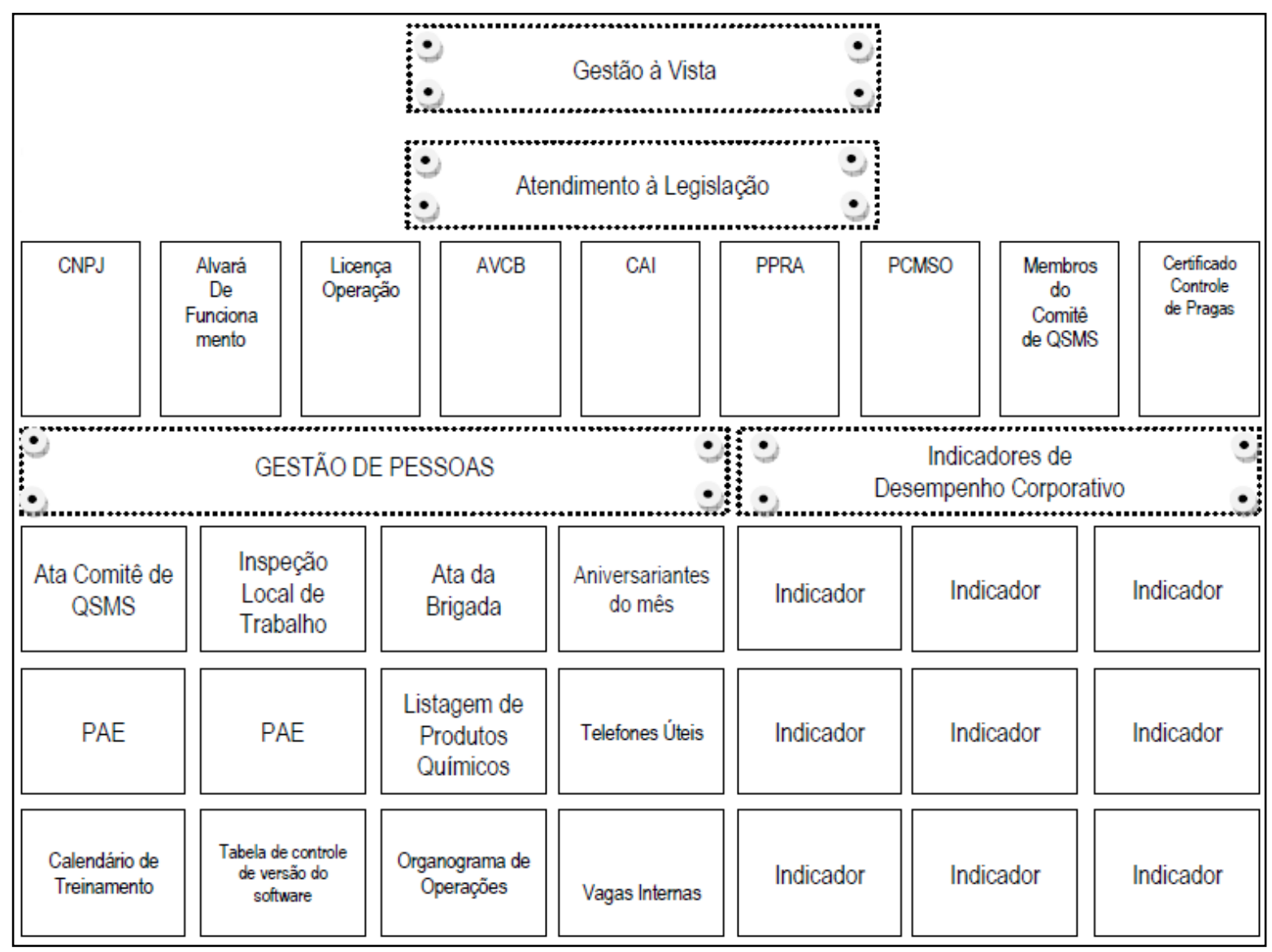

Figura 3: exemplo de Gestão à Vista encontrada em cada Centro de Inspeção.

\section{O SISTEMA DE GESTÃO INTEGRADO (SGI)}

O SGI foi a decisão encontrada pela alta administração com o propósito de acelerar o amadurecimento dos processos existentes com base aos procedimentos internos e externos. A implantação e manutenção do sistema de gestão de processos visou o atendimento aos requisitos das três normas, simultaneamente, que são: ABNT NBR ISO 9001:2008 - Sistema de Gestão da Qualidade, ABNT NBR ISO 14001:2004 - Sistema da Gestão Ambiental e OHSAS 18001:2007 - Sistema de Gestão da Segurança e Saúde no Trabalho. 
Esta decisão estratégica permitiu que a partir de 2010 houvesse um ganho na sistemática de controle e atendimento aos requisitos legais, afim de demonstrar seu desempenho referente à qualidade, meio ambiente e na segurança e saúde ocupacional.

O SGI possibilitou a integração da tecnologia, pessoas e legislação em uma empresa recémcriada de modo que os funcionários contratados de diferentes seguimentos do mercado pudessem em um curto período de tempo focar os trabalhos por um esforço em comum.

Após a implantação, as rotinas de auditorias anualmente internas, externas e aos requisitos legais avaliaram se o sistema estabelecido pela organização permanecia implantada e mantida, atendendo aos requisitos estabelecidos nas normas de referência por meio dos procedimentos definidos pela organização.

A estrutura do SGI permitiu o envolvimento de todos os níveis de funcionários, isto é, foi definida uma política do SGI pela alta administração em função da estratégia de negócio e organização por meio da missão, visão e valores.

A missão é amplamente divulgada nas unidades de negócio e tem a seguinte mensagem: "Melhorar a qualidade do ar na cidade de São Paulo, reduzindo a poluição através da inspeção ambiental veicular e gerar resultados para a sociedade, colaboradores e acionistas".

A visão foi se alterando conforme o aprendizado junto com a sociedade na prestação de serviço e hoje tem a seguinte mensagem: "Ser reconhecida e admirada pela excelência e responsabilidade na prestação de serviços, respeito à sociedade e por sua contribuição ao meio ambiente e saúde pública”.

Os valores da empresa são palavras normalmente utilizadas nas tomadas de decisão, que muitas vezes são utilizadas como argumentação e convencimento de pontos de vistas divergentes em reuniões. Os valores são: comprometimento, desenvolvimento sustentável, ética, excelência e transparência.

O nível gerencial preparou o manual do SGI que define o sistema de gestão integrado. A partir deste ponto foi criado o fluxo de atividades que envolvem uma determinada atividade com os macroprocessos. Por fim, os procedimentos, instruções de trabalho e registros aplicados ao nível operacional.

Também um procedimento referente à gestão do centro de inspeção foi aplicado e atualmente é o manual do gerenciamento do centro de inspeção nas tomadas de decisões, no cumprimento legal e nas rotinas estabelecidas, que garantem a padronização não só na inspeção ambiental, mas também na governança das unidades.

Com os processos executados, foram criadas as rotinas de reuniões no nível gerencial e operacional, que faz parte do manual de gerenciamento e possibilita a discussão de oportunidades de melhoria na operação e no apoio à execução da inspeção.

Deste modo o SGI fecha o ciclo de melhoria de modo que a execução dos trabalhos estejam uniformizados e alinhados com a política da empresa. 


\section{CONCLUSÕES}

Os centros de inspeção estão preparados e constantemente são melhorados para atender os munícipes na cidade de São Paulo, independentemente do tipo de veículo e ano de fabricação a ser inspecionado.

Os controles internos quanto à emissão de poluentes e de ruído no local que se efetua na inspeção são analisados anualmente e estabelecidos na rotina de gerenciamento de cada unidade.

As rotinas diárias referentes à verificação do sistema em conjunto com as redundâncias de equipamentos instalados, possibilita uma disponibilidade de $99,99 \%$ na presente data, sendo este um indicador de desempenho corporativo.

A criação dos níveis hierárquicos possibilita que os funcionários constantemente almejem novos postos de trabalhos, tanto em níveis operacionais como gerenciais de forma que o turnover de saída espontânea do emprego atende a níveis baixos de solicitações.

O sistema gerencial Balance Scorecard trouxe um salto no aprendizado, crescimento, padronização e rigor no cumprimento da legislação, pois permitiu alcançar todos os níveis operacionais e gerenciais ao mesmo tempo, com foco em um esforço em comum.

Os indicadores definidos em quatro perspectivas; iniciando se pelas competências em constantes treinamentos; processos internos com a definição dos macroprocessos principais, de apoio e gerenciais; mercados e clientes com resultados das competências e processos, e por último; os resultados financeiros como consequência de todo o trabalho de base, concretizou um trabalho gerencial com ações sistêmicas em todos os níveis da operação e de apoio à inspeção ambiental.

O SGI acelerou o aprendizado, tornando os processos definidos e melhorados por meio de revisões constantes, de forma que ao longo dos anos de implantação e re-certificação, houve uma complexidade no gerenciamento, porém os documentos no cumprimento dos trabalhos tornaram-se naturalmente mais simples no acesso e entendimento corporativo.

A comunicação dos resultados da inspeção e envio eletrônico diário de todas as informações das inspeções à PRODAM, para liberação automática do licenciamento dos veículos aprovados na inspeção ambiental, permitiu total confidencialidade nas informações processadas.

A uniformização dos resultados devido ao sistema de gestão integrada e de concessão centralizado contribui na divulgação de dados consistentes que habilitam estudos pela Faculdade de Medicina da Universidade de São Paulo (FMUSP), pela empresa Controlar, e também, para futuros projetos em grupos de trabalho coordenados pela Associação dos Engenheiros Automotivos (AEA), assim como base em propostas futuras para os limites de inspeção ambiental veicular. 


\section{REFERÊNCIAS BIBLIOGRÁFICAS}

ABNT NBR ISO 9001:2008 - Sistema de Gestão da Qualidade.

ABNT NBR ISO 14001:2004 - Sistema da Gestão Ambiental.

BRANCO, G.M. et al; Programa Ambiental de Inspeção e Manutenção Veicular, $1^{\text {a }}$ edição, Blucher, 2012.

CAMPOS, V.F., Gerenciamento da rotina de trabalho no dia a dia, $8^{a}$ edição, INDG Tecnologia e Serviços Ltda., 2004.

CAMPOS, V. F., Qualidade Total, Xa edição, INDG Tecnologia e Serviços Ltda., 1999.

CONTROLAR, publicação do balanço anual, 2011.

INSTRUÇÃO NORMATIVA n ${ }^{\circ} 06$ do IBAMA - Instituto Brasileiro do Meio Ambiente e dos Recursos Naturais Renováveis, 2010.

KAPLAN, S. R., NORTON, D. P., A Estratégia em Ação - Balanced Scorecard, 32a edição, Elsevier, 1997.

OHNO, T., O Sistema Toyota de Produção, reimpressão, Bookman, 1997.

OHSAS 18001:2007 - Sistema de Gestão da Segurança e Saúde no Trabalho.

PORTARIA 3214/78, Ministério do Trabalho - Norma Regulamentadora nº 09, 1978.

PORTARIA 25/94, Ministério do Trabalho - Norma Regulamentadora $n^{\circ} 07$ - Programa de Controle Médico de Saúde Ocupacional (PCMSO), 1994.

RESOLUÇÃO nº 418 do CONAMA - Conselho Nacional do Meio Ambiente, 2009.

SLACK, N. et al., Administração da Produção, $3^{\text {a }}$ edição, Atlas, 2009. 